\title{
Nonlinear Sorption of Organic Contaminant during Two-Dimensional Transport in Saturated Sand
}

\author{
Sang-Gil Lee ${ }^{1}$, Soonjae Lee ${ }^{1, *(D)}$ and Jae-Woo Choi ${ }^{2, *(D)}$ \\ 1 Department of Earth and Environmental Sciences, Korea University, Anam-ro 145, Sungbuk-gu, \\ Seoul 02841, Korea; sg0403@korea.ac.kr \\ 2 Center for Water Resources Cycle Research, Korea Institute of Science and Technology, Hwarang-ro 14-gil 5, \\ Seongbuk-gu, Seoul 02792, Korea \\ * Correspondence: soonjam@korea.ac.kr (S.L.); plead36@kist.re.kr (J.-W.C.); Tel.: +82-2-3290-3177 (S.L.); \\ +82-2-958-5820 (J.-W.C.)
}

check for updates

Citation: Lee, S.-G.; Lee, S.; Choi, J.-W. Nonlinear Sorption of Organic Contaminant during Two-Dimensional Transport in Saturated Sand. Water 2021, 13, 1557. https://doi.org/10.3390/w13111557

Academic Editor:

Alexander Yakirevich

Received: 9 May 2021

Accepted: 30 May 2021

Published: 31 May 2021

Publisher's Note: MDPI stays neutral with regard to jurisdictional claims in published maps and institutional affiliations.

Copyright: (c) 2021 by the authors. Licensee MDPI, Basel, Switzerland. This article is an open access article distributed under the terms and conditions of the Creative Commons Attribution (CC BY) license (https:/ / creativecommons.org/licenses/by/ $4.0 /)$.

\begin{abstract}
Multi-dimensional transport studies are necessary in order to better explain the fate of contaminants in groundwater. In this study, a two-dimensional transport experiment with organic contaminants in saturated sand was conducted to investigate the migration of the organic contaminant plume in multi-dimensional flow conditions. The transport test was conducted using toluene as a model organic contaminant in a saturated sand box under steady flow conditions. The initial plume was generated via injection at a point source. After $24 \mathrm{~h}$, the plume distribution was delineated by interpolating toluene concentrations in the porewater samples. The mass centers of the toluene and the conservative tracer were almost coincident, but the size of the toluene plume was significantly reduced in longitudinal as well as transversal directions. The appropriateness of several types of sorption models were compared to describe the toluene sorption in two-dimensional transport system using numerical modeling. Among the sorption models, the Langmuir model was found to be the most appropriate to describe the sorption of toluene during two-dimensional transport. The results showed that two-dimensional experiments are better than one-dimensional column experiments in identifying the adsorption characteristics that occur during transport in saturated aquifers.
\end{abstract}

Keywords: 2D sand box; toluene; transport; sorption; reversibility; local equilibrium assumption; non-linear isotherm

\section{Introduction}

The leakage of petroleum oil from facilities designed for transport and storage is one of the major sources of groundwater contamination. Leaked oil penetrates into the underground environment and forms a non-aqueous liquid (NAPL) pool above or below the aquifer. Various contaminants are continuously supplied into the groundwater through the dissolution of organic compounds from the NAPL pool. The presence of organic contaminants in the groundwater could pose a serious hazard to public health and the environment. For example, one of the most common hydrocarbon contaminants in soil and groundwater is BTEX (benzene, toluene, ethylbenzene, xylene) [1]. BTEX compounds are more toxic than liquid alkanes and are well-known toxicants to a wide range of biota [2]. Benzene is an International Agency for Research on Cancer (IARC)-classified group I carcinogen, ethylbenzene is a suspected IIB carcinogen, and both toluene and xylenes are IARC group III neurotoxins [3]. Groundwater contaminated by BTEX is a very serious problem because many communities in the world depend upon groundwater as a sole or major source of drinking water [4]. USEPA reported that the maximum levels for monoaromatic compounds in potable water are $0.05,1,0.7$ and $10 \mathrm{mg} / \mathrm{L}$ for benzene, toluene, ethylbenzene and isomers of xylenes, respectively [5].

Among these, toluene is used in various fields for many purposes, such as a solvents in paint, lacquers, thinner, glue and nail polish, as well as in leather tanning [6,7]. It is 
also used as an octane booster in gasoline fuels in internal combustion engines, and in cosmetic and personal care products [8-10]. Therefore, toluene has been reported as a potential substance which can contaminate groundwater and soil. In particular, toluene is known to be a degradable material in the underground environment, but analysis of the transport characteristics of toluene is very important, since the removal rate can be changed, depending on environmental conditions. It is necessary to confirm whether the natural attenuation process can be degraded based on the prediction of the behavior of toluene when underground environmental pollution occurs due to an intensified toluene spill [11].

The fate of organic contaminants in groundwater is controlled by advective and dispersive mass transfer, as well as attenuation associated with sorption [12]. The sorption processes in the subsurface environment are very complex, often involving non-linear phase relationships and rate-limited conditions [13]. The sorption of an organic compound on the aquifer material affects the distribution of contaminants and is important in understanding the fate of the contaminant in the aquifer. The adsorption of organic compounds onto the aquifer material is highly dependent on the organic matter in the soil $\left(\mathrm{f}_{\mathrm{oc}}\right)$, as well as the surface area related to the clay contents $[13,14]$. Because the critical level of soil organic matter is low $(0.1 \%$ for the case of benzene), the adsorption of organic contaminant onto the aquifer is mostly dominated by the hydrophobic reaction of soil organic matter. In field conditions, heterogeneous soil properties, such as organic matter, further complicate the fate of organic contaminants [15-17].

Hydrophobic adsorption studies have been conducted on organic pollutants in soil under various conditions [18]. The adsorption reaction between clay minerals and organic substances in the soil causes adsorption, leading to heterogeneous adsorbents [19]. The distribution of pollutants in soil and groundwater can be explained by non-linear forms of the Langmuir and Freundlich isotherm models [20]. The Langmuir sorption model estimates monolayer adsorption for adsorbents, whereas the Freundlich model is commonly applicable to heterogeneous sorption [21]. The characteristics of non-linear sorption do not appear when the concentration of organic pollutants is low; therefore, it can be explained with a linear sorption isotherm [22].

Numerous experimental and modeling studies have been performed at laboratoryand/or field-scales to examine the effect of the sorption of organic contaminants onto aquifer materials and its effects on their transport phenomena [14,23-33]. In particular, column experiments have been frequently used to investigate the fate of organic contaminants [26]. Several laboratory column studies have shown the attenuation of organic contaminants during transport [27-29]. The retardation of organic pollutants has also been reported in one-dimensional column experiments, as well as in the two-dimensional sand box test [30-32]. In several field studies, highly retarded transport trends were reported for hydrophobic compounds [33]. Long-term experiments at the site scale (Borden, Ontario) confirmed the occurrence of retardation, along with attenuation, and this behavior could be successfully explained using the linear equilibrium approach [14].

The equilibrium approach using a partitioning coefficient $\left(\mathrm{K}_{\mathrm{d}}=\mathrm{f}_{\mathrm{OC}} \times \mathrm{K}_{\mathrm{oc}}\right)$ is widely used to describe sorption during the transport of organic contaminants in aquifers [14,30-32]. However, the linear sorption property is not applicable in all aspects. Previous studies have reported on the differences in the retardation caused by non-linear and linear sorption using a one-dimensional column [34,35]. When the content of organic matter in the soil is low, the functional groups in soil which can react with pollutants may be saturated within a limited time. In this case, it may appear that irreversible sorption has occurred on the soil surface during the transport of pollutants due to the termination of the sorption reaction because of saturation. To confirm this reaction, it is necessary to conduct a test on the transport of pollutants through a multi-dimensional laborator-scale model experimental apparatus. We thought that the two-dimensional transport test could reflect the transport characteristics at the contaminated site better than the one-dimensional test as a method of the laboratory test. 
The objective of this study was to investigate the type of sorption that occurred during the transport of an organic contaminant in two-dimensional saturated aquifer material. Here, toluene was selected as a representative contaminant among the organic pollutants frequently detected in contaminated groundwater, and was used as a tracer for the natural attenuation and the fate of contaminants in the subsurface environment due to its high solubility and biodegradability. Their sorption type during transport was determined by comparing observed plumes with the simulated results, considering various sorption models. All these results were supported and described in detail by conducting numerical modeling. Furthermore, the nonlinear equilibrium adsorption model was more appropriate for estimating the retardation factor to explain the retardation of organic pollutants.

\section{Materials and Methods}

\subsection{Two-Dimensional Plume Experiments}

\subsubsection{Sand Box Model}

Plume tests were performed in a two-dimensional physical aquifer model (Figure 1 ) which was constructed using polycarbonate with dimensions of $60 \mathrm{~cm}(\mathrm{~L}) \times 30 \mathrm{~cm}(\mathrm{~W}) \times$ $2 \mathrm{~cm}(\mathrm{H})$. Five ports with a diameter of $10 \mathrm{~mm}$ were positioned at $5-\mathrm{cm}$ regular intervals on the left and right sides of the model to induce inflow and outflow during plume tests, respectively. Sampling ports of 171 units with a diameter of $7 \mathrm{~mm}$ were installed at the top of the aquifer model with a grid of $9 \times 19$ and capped by Teflon-coated rubber cap. To minimize air entrapment, the aquifer model standing in the longitudinal direction was filled with background liquid and then was uniformly packed with sandy soil, which mainly consisted of quartz (Jumunjin silica, Korea). Mechanical sieving of sandy material was performed using US Standard Sieves (Fisher Scientific, Waltham, MA, USA) No. 30 and No. 10 to obtain sand fractions $(0.6 \sim 2.0 \mathrm{~mm})$. Before experimental use, the sandy materials were washed using deionized water three times and autoclaved twice at $121^{\circ} \mathrm{C}$ for $15 \mathrm{~min}$ to prevent any influence by other microorganisms. The bulk density and porosity of the sandy soil were determined to be $1.54 \mathrm{~g} / \mathrm{cm}$ and 0.35 , respectively. The sand was analyzed using an X-ray diffraction technique and was found to be mainly composed of quartz with very little organic carbon $(<0.05 \%)$ [36].

(a)
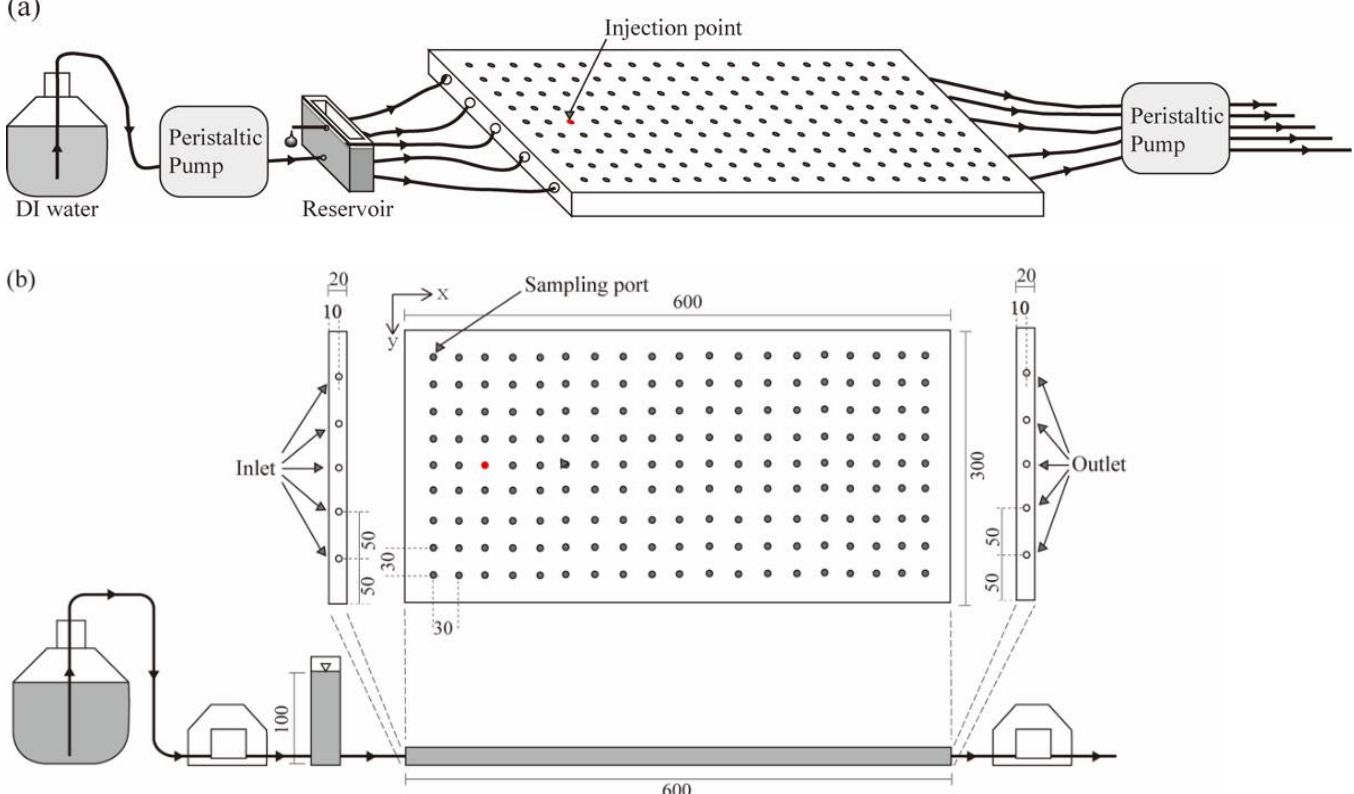

Figure 1. (a) Laboratory system for two-dimensional solute transport experiments; (b) layout of aquifer model (top view and front view). 


\subsubsection{Two-Dimensional Solute Transport Experiments}

To test the fate and transport of organic pollutants in saturated media, solute transport experiments using toluene and $\mathrm{KCl}$ were performed in the sand box model. Steady-state flow conditions were imposed on the aquifer by applying a constant head $(\Delta \mathrm{h}=7 \mathrm{~cm})$ and constant flux $(\mathrm{Q}=22.68 \mathrm{~mL} / \mathrm{h})$ of DI water at the inflow side through a reservoir and a peristaltic pump, respectively. Once steady-state flow conditions were reached, tracer solutions were applied into the injection point of the aquifer model $(x=12 \mathrm{~cm}, y=15 \mathrm{~cm})$ for $6 \mathrm{~min}$, using a syringe with injection rate $\mathrm{q}_{\text {in }}=10 \mathrm{~mL} / \mathrm{min}$. In the first case, a conservative tracer transport experiment was performed, using $\mathrm{KCl}$ to confirm the properties of solute transport through the advection dispersion process, except adsorption. This was carried out by injecting $60 \mathrm{~mL}$ of $\mathrm{KCl}$ solution at a concentration of $150 \mathrm{mg} / \mathrm{L}$ to investigate the dispersion of the solute. In the next case, $60 \mathrm{~mL}$ of toluene solution at a concentration of $200 \mathrm{mg} / \mathrm{L}$ were injected to investigate the effect of toluene sorption. Initial plumes of $\mathrm{KCl}$ and toluene were measured using separate additional tests. Samples were collected from the sampling port $24 \mathrm{~h}$ after the tracer injection. A minimum number of samples were collected using a 1-mL syringe in radial directions based on the expected center of the solute plume to minimize disturbance during sampling and to maximize the detection efficiency. $\mathrm{KCl}$ concentrations were analyzed using an electrical conductivity (EC) meter (Orion, Model: 130A, Hamburg, Germany). The toluene concentration was analyzed using HPLC (Young Lin, Seoul, Korea).

\subsubsection{Moment Analysis for Solute Plume}

Two-dimensional plumes can be characterized using moment analysis, which can express mass recovery and the center of mass. The travel distance of plumes were obtained as the distance from the injection point to the mass center of the plume. The mass center of plume was determined based on the calculation of the first raw moment, using moment analysis [37]. The coordinate location of the center of mass $\left(x_{c}, y_{c}\right)$ was as follows:

$$
\begin{aligned}
& x_{c}=\iint n C(x, y) x d x d y / \iint n C(x, y) d x d y \\
& y_{c}=\iint n C(x, y) y d x d y / \iint n C(x, y) d x d y
\end{aligned}
$$

where $C(x, y)$ is concentration field $(\mathrm{M} / \mathrm{L}), n$ is porosity $(-)$ and $x, y$ are the coordinates (L).

The mass recovery of the $\mathrm{KCl}$ plume was determined based on the calculation of the observed mass using the inverse distance weighted interpolation method in GMS (version 10.3.4, Aquaveo, Prove, UT, USA). The mass recovery of tracer (Mr) was as follows:

$$
\mathrm{Mr}=\iint n C(x, y) d x d y /\left(C_{0} \times t_{0} \times q_{\text {in }}\right)
$$

where $C_{0}$ is the concentration of the injected tracer $\left(\mathrm{M} / \mathrm{L}^{3}\right), t_{0}$ is injected time $(\mathrm{T})$ and $q_{\text {in }}$ is injection flow rate $\left(\mathrm{L}^{3} / \mathrm{T}\right)$.

\subsection{Modeling Water Flow and Solute Transport}

Two-dimensional solute transport was simulated using two different codes in the GMS (Aquaveo, Provo, UT, USA) environment. First, the flow part was executed using the modular three-dimensional finite-difference groundwater flow model (MODFLOW) code [38], the mathematical model simulating flow, using the partial-differential equation:

$$
\frac{\partial}{\partial x}\left(K_{x x} \frac{\partial h}{\partial x}\right)+\frac{\partial}{\partial y}\left(K_{y y} \frac{\partial h}{\partial y}\right)+\frac{\partial}{\partial z}\left(K_{z z} \frac{\partial h}{\partial z}\right)-W=S_{s} \frac{\partial h}{\partial t}
$$

where $K_{x x}, K_{y y}$ and $K_{z z}$ are the hydraulic conductivity along the $\mathrm{x}, \mathrm{y}$ and $\mathrm{z}$ axes, respectively, which are assumed to be parallel to the major axis of the hydraulic conductivity $(\mathrm{L} / \mathrm{T})$; $\mathrm{h}$ is the potentiometric head (L); $\mathrm{W}$ is the volumetric flux per unit value, representing sources 
and/or sinks of water $(1 / \mathrm{T}) ; \mathrm{S}_{\mathrm{S}}$ is the specific storage of porous material $(1 / \mathrm{L})$; and $\mathrm{t}$ is the time. The modeling domain was constructed with $62 \times 31$ grid cells and boundary conditions were as follows: the five source points (inlet ports) on the left side had constant head boundary conditions $(\mathrm{h}=7 \mathrm{~cm})$, the five sink points (outlet ports) on the right side had constant flux $\left(4.536 \mathrm{~cm}^{3} / \mathrm{h}\right)$, and the rest of the boundary was set as a no-flux boundary. The simulation conditions for two-dimensional water flow are listed in Table 1.

Table 1. Parameters used in the modeling of two-dimensional water flow.

\begin{tabular}{ccc}
\hline Parameter & Value & Source \\
\hline Inflow: constant head & $7 \mathrm{~cm}$ & This study \\
Outflow: recharge source, $\mathrm{W}$ & $22.68 \mathrm{~cm}^{3} / \mathrm{h}$ & This study \\
Hydraulic conductivity, $\mathrm{K}_{\mathrm{xx}}, \mathrm{K}_{\mathrm{yy}}, \mathrm{K}_{\mathrm{zz}}$ & $96.6 \mathrm{~cm} / \mathrm{h}$ & {$[39]$} \\
Porosity of porous material, $\mathrm{n}$ & 0.35 & This study \\
Bulk density of porous material, $\rho_{\mathrm{s}}$ & $1.57 \mathrm{~g} / \mathrm{cm}^{3}$ & This study \\
\hline
\end{tabular}

Reactive solute transport was modeled using MT3D [40]. The general macroscopic equations describing the fate and transport of aqueous- and solid-phase species, respectively, in multi-dimensional saturated porous media are written as

$$
\frac{\partial C}{\partial t}=\frac{\partial}{\partial x_{i}}\left(D_{i j} \frac{\partial C_{k}}{\partial x_{j}}\right)-\frac{\partial}{\partial x_{i}}\left(v_{i} C\right)+\frac{q_{s}}{\theta} C_{s}+r_{c}
$$

where $C$ is the aqueous-phase concentration $\left(\mathrm{M} / \mathrm{L}^{3}\right), D_{i j}$ is the hydrodynamic dispersion coefficient $\left(\mathrm{L}^{2} / \mathrm{T}\right), v_{i}$ is the pore velocity $(\mathrm{L} / \mathrm{T}), \theta$ is the soil porosity, $q_{s}$ is the volumetric flux of water per unit volume of aquifer representing sources and sinks $(1 / \mathrm{T}), C_{s}$ is the concentration of source/sink $\left(\mathrm{M} / \mathrm{L}^{3}\right)$, and $r_{c}$ represents the rate of all reactions that occur in the aqueous phase $\left(\mathrm{ML}^{3} / \mathrm{T}\right)$.

The mobile species transport Equation (5) is first divided into four distinct equations: the advection equation, the dispersion equation, the source/sink-mixing equation, and the reaction equation. The reaction term in Equation (7) can be used to include the effect of geochemical reactions $\left(\mathrm{r}_{\mathrm{cg}}\right)$ on contaminant fate and transport. The sorption of the solute can be described using two different models, assuming that the process follows equilibrium and kinetic irreversible sorption. These models were used independently to describe the solute sorption process during transport through saturated porous media.

$$
r_{c g}=\frac{\rho_{s}}{\theta} \frac{\partial S_{e q}}{\partial t}+\frac{\rho_{s}}{\theta} \frac{\partial S_{i r r}}{\partial t}
$$

where the subscript $e q$ and irr indicate equilibrium and kinetic irreversible sorption reaction, respectively. There are three types of equilibrium isotherms-linear, Freundlich and Langmuir in general. The sorption process in the linear isotherm can be represented as

$$
\frac{\partial S_{e q}}{\partial t}=K_{d} \frac{\partial C_{k}}{\partial t}
$$

where $K_{d}$ is the distribution coefficient $\left(\mathrm{L}^{3} / \mathrm{M}\right)$. Equilibrium sorption isotherms are generally incorporated into the transport model through the use of the retardation factor $(R)$. The retardation factor can be represented as

$$
R=1+\frac{\rho_{s}}{\theta} K_{d}
$$


where $\rho_{s}$ is the dry bulk density of soil $\left(\mathrm{M} / \mathrm{L}^{3}\right)$. The sorption process in the Freundlich isotherm can be represented as

$$
\begin{gathered}
\frac{\partial S_{e q}}{\partial t}=K_{f}\left(\frac{\partial C_{k}}{\partial t}\right)^{a} \\
R=1+\frac{\rho_{s}}{\theta} a K_{f} C_{k}^{a-1}
\end{gathered}
$$

where $K_{f}$ is the Freundlich constant $\left(\left(\mathrm{L}^{3} / \mathrm{M}\right)^{\mathrm{a}}\right)$ and $a$ is the Freundlich exponent $(-)$. The sorption process in the Langmuir isotherm can be represented as

$$
\begin{gathered}
\frac{\partial S_{e q}}{\partial t}=\frac{K_{l} b \frac{\partial C_{k}}{\partial t}}{1+K_{l} \frac{\partial C_{k}}{\partial t}} \\
R=1+\frac{\rho_{s}}{\theta}\left[\frac{K_{l} b}{\left(1+K_{l} C_{k}\right)^{2}}\right]
\end{gathered}
$$

where $K_{1}$ is the Langmuir constant $\left(\mathrm{L}^{3} / \mathrm{M}\right)$, and $b$ is the total concentration of sorption sites available $(\mathrm{M} / \mathrm{M})$. The sorption process in a kinetic irreversible site can be represented as

$$
\frac{\rho_{s}}{\theta} \frac{\partial S_{i r r}}{\partial t}=k_{i r r} C_{k}
$$

where $k_{i r r}$ is $(1 / \mathrm{T})$.

\subsection{Optimization of Parameters}

The dispersion coefficient and sorption parameters were optimized through the comparison of the observed plume with those simulated. The solute concentration function is denoted as $C=f(X, t ; p)$, where the vector $p$ represents the parameters and $X$ is the location of observation $(x, y)$. To optimize the dispersion coefficient, the observed and the simulated $\mathrm{KCl}$ plumes were compared, and the parameter $p=\left(D_{x}, D_{y}\right)$. To optimize the sorption coefficients, the observed and the simulated toluene plumes were compared, where the parameter $p=\left(k_{i r r}\right)$ was used for irreversible kinetic sorption, $p=\left(K_{d}\right)$ for a linear isotherm, $p=\left(K_{f}, a\right)$ for a Freundlich isotherm, and $p=\left(K_{l}, b\right)$ for a Langmuir sorption isotherm. The parameter domain was constrained so that $\Omega=\left[a_{1}, b_{1}\right]$ for single-parameter models and $\Omega=\left[a_{1}, b_{1}\right] \times\left[a_{2}, b_{2}\right]$ for two-parameter models, where the values of $a_{n}$ and $b_{n}$ are the minimum and maximum boundaries, respectively. For $m$ observation data at time $t$, $E=\left\{\left(X_{i}, C_{i}\right) \mid i=1, \ldots, m\right\}$ is denoted as the set of the data. Then, the error function is defined as

$$
e(p)=\sum_{i=1}^{m}\left(C_{i}-f\left(X_{i} ; p_{i}\right)\right)^{2}
$$

The discretized domain (DD) algorithm was used to determine the best parameters that could minimize $e(p)$ for given parameter domain $\Omega$ [41]. The boundaries and intervals used for the optimization algorithm are listed in Table 2. For the estimation of parameters with high resolution, the DD algorithm was repeatedly used in the finer mesh around the optimal point found by the preceding DD algorithm. For discretization of the parameter domain of single- parameter models, let $N_{1}$ be positive integers, let

$$
\Omega=\left\{x_{i} \mid \log \left(x_{i}\right)=a_{1}+\frac{i}{N_{1}}\left(b_{1}-a_{1}\right), 0 \leq \mathrm{i} \leq N_{1}\right\}
$$

be the set of nodes for preceding optimization, and let

$$
\Omega=\left\{x_{i} \mid x_{i}=a_{1}+\frac{i}{N_{1}}\left(b_{1}-a_{1}\right), 0 \leq \mathrm{i} \leq N_{1}\right\}
$$


be the set of nodes for the final optimization. For the discretization of the parameter domain of two-parameter parameters models, let $N_{1}$ and $N_{2}$ be positive integers, let

$$
\Omega=\left\{\left(x_{i}, y_{j}\right) \mid \log \left(x_{i}\right)=a_{1}+\frac{i}{N_{1}}\left(b_{1}-a_{1}\right), \log \left(y_{i}\right)=a_{2}+\frac{j}{N_{2}}\left(b_{2}-a_{2}\right), 0 \leq \mathrm{i} \leq N_{1}, 0 \leq \mathrm{j} \leq N_{2}\right\}
$$

be the set of mesh grids for preceding optimization, and let

$$
\Omega=\left\{\left(x_{i}, y_{j}\right) \mid x_{i}=a_{1}+\frac{i}{N_{1}}\left(b_{1}-a_{1}\right), y_{i}=a_{2}+\frac{j}{N_{2}}\left(b_{2}-a_{2}\right), 0 \leq \mathrm{i} \leq N_{1}, 0 \leq \mathrm{j} \leq N_{2}\right\}
$$

be the set of mesh grids for the final optimization. Then the minimum error can be approximated by min $e(p)$ for $p \in \Omega$ and values corresponding to this error can be chosen to be the best parameter set.

\begin{tabular}{|c|c|c|c|c|c|c|}
\hline & $\begin{array}{c}\text { Irreversible } \\
k_{i r r}(1 / \mathrm{h})\end{array}$ & $\begin{array}{c}\text { Linear } \\
K_{d}\left(\mathrm{~cm}^{3} / \mathrm{mg}\right)\end{array}$ & $\begin{array}{c}\text { Freundlich } \\
K_{f}\left(\mathrm{~cm}^{3} / \mathrm{mg}\right)\end{array}$ & $a(-)$ & $\begin{array}{c}\text { Langmuir } \\
K_{l}\left(\mathrm{~cm}^{3} / \mathrm{mg}\right)\end{array}$ & $b(\mathrm{mg} / \mathrm{mg})$ \\
\hline Boundary & $\left(1.0 \times 10^{-5}, 1\right)$ & $\left(1.0 \times 10^{-9}, 1\right)$ & $\begin{array}{l}\left(1.0 \times 10^{-6}, 1.0\right. \\
\left.\quad \times 10^{-3}\right)\end{array}$ & $\left(1.0 \times 10^{-9}, 1\right)$ & $\left(1,1.0 \times 10^{4}\right)$ & $\left(1.0 \times 10^{-5}, 1\right)$ \\
\hline Ratio $^{1}$ & 10 & 10 & 10 & 10 & 10 & 10 \\
\hline Boundary & $(0.001,0.2)$ & $\begin{array}{c}\left(1.0 \times 10^{-8}, 1.0\right. \\
\left.\times 10^{-3}\right)\end{array}$ & $\begin{array}{l}\left(1.0 \times 10^{-5}, 2.0\right. \\
\left.\quad \times 10^{-4}\right)\end{array}$ & $(0.001,0.1)$ & $(2300,2500)$ & $\begin{array}{l}\left(5.7 \times 10^{-4}, 5.9\right. \\
\left.\quad \times 10^{-4}\right)\end{array}$ \\
\hline Interval & 0.01 & 0.0001 & 0.0001 & 0.01 & 2400 & 0.00058 \\
\hline
\end{tabular}

Table 2. Boundary values and intervals of parameters used for optimization algorithm.

${ }^{1}$ At the first optimization, the parameter domain was discretized in a logarithmic scale.

\section{Results and Discussion}

\subsection{Two-Dimensional Transport of Toluene and KCl Plumes}

Observed plumes of $\mathrm{KCl}$ at $24 \mathrm{~h}$ after tracer injection are shown in Figure 2a. The results of moment analysis are listed in Table 3 . The calculated mass center of the $\mathrm{KCl}$ plumes was located at $(x, y)=(37.65,14.72)$. The travel distance from the injection point to the mass center of the $\mathrm{KCl}$ plumes was $25.65 \mathrm{~cm}$. The average linear velocity $\left(v_{x}\right)$ was obtained as $1.069 \mathrm{~cm} / \mathrm{h}$. The mass recovery of $\mathrm{KCl}$ was $100.4 \%$, respectively. The $\mathrm{KCl}$ plume at $24 \mathrm{~h}$ showed nearly a circular pattern with little distortion (Figure 2a).
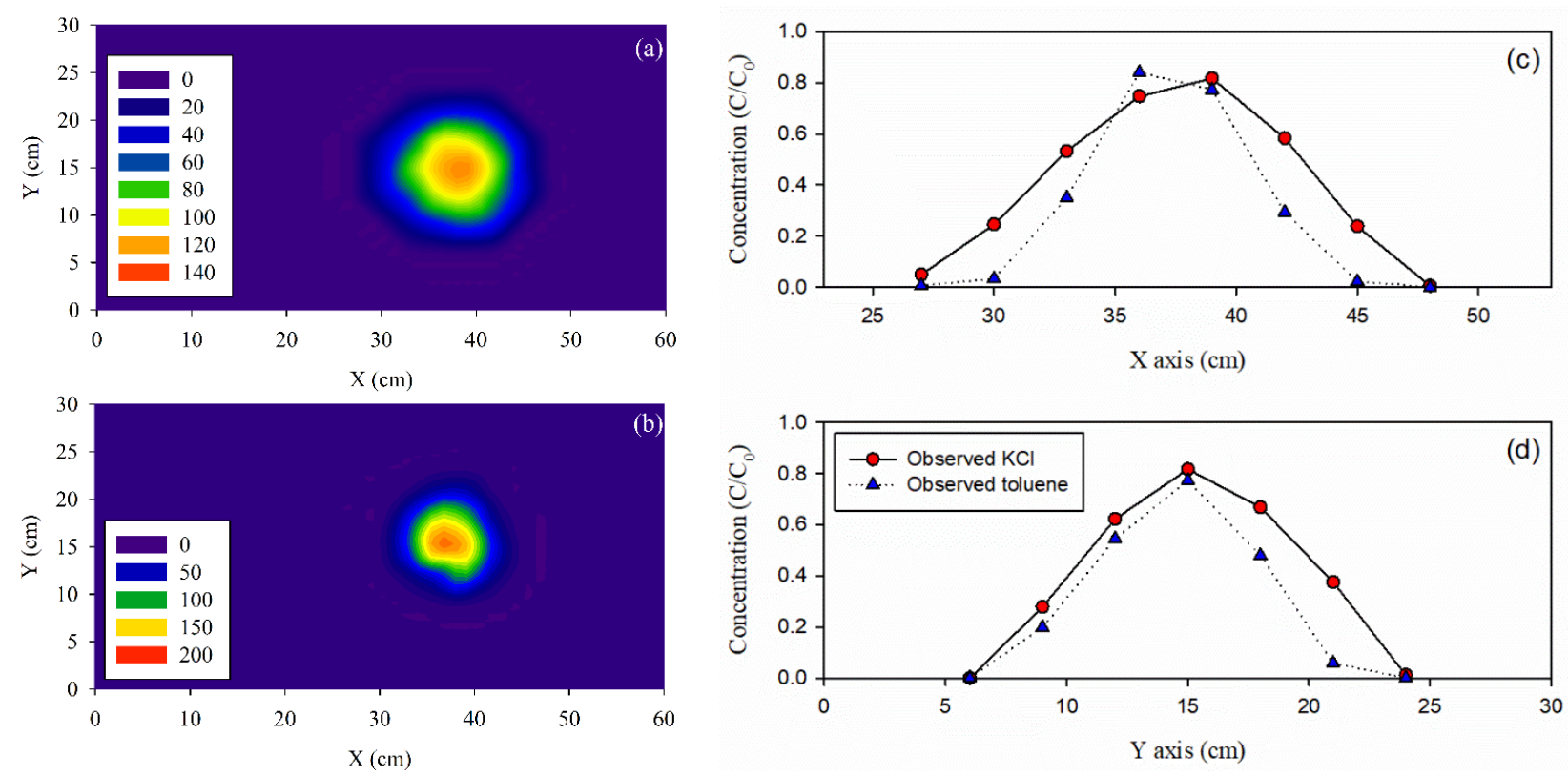

Figure 2. Observed (a) $\mathrm{KCl}$ and (b) toluene plumes at $24 \mathrm{~h}$ (unit of contour $\mathrm{mg} / \mathrm{L}$ ). Concentration distribution of toluene and $\mathrm{KCl}$ plume: $(\mathbf{c})$ longitudinal direction $($ at $\mathrm{y}=15 \mathrm{~cm})$ and $(\mathbf{d})$ transverse direction $($ at $\mathrm{x}=39 \mathrm{~cm})$. 
Table 3. Mass center and mass recovery of observed and modeled $\mathrm{KCl}$ and toluene plumes obtained through moment analysis.

\begin{tabular}{|c|c|c|c|c|c|c|}
\hline Cases & $\begin{array}{c}\mathrm{KCl} \\
(\mathrm{mg} / \mathrm{L})\end{array}$ & $\begin{array}{l}\text { Toluene } \\
\text { (mg/L) }\end{array}$ & $\begin{array}{c}\text { Mass Center } \\
(x, y)\end{array}$ & $\begin{array}{l}\text { Velocity } \\
(\mathrm{cm} / \mathrm{h})\end{array}$ & $\begin{array}{c}\text { Mass Recovery } \\
(\%)\end{array}$ & Remark \\
\hline K0 & 150 & - & $(11,15)$ & - & - & Obs. at $0 \mathrm{~h}$ \\
\hline K24 & 150 & - & $(37.65,14.72)$ & 1.069 & 100.4 & Obs. at $24 \mathrm{~h}$ \\
\hline $\mathrm{T} 24$ & - & 200 & $(37.25,14.35)$ & 1.052 & 60.2 & Obs. at $24 \mathrm{~h}$ \\
\hline $\mathrm{K} 0 \mathrm{~m}$ & 150 & - & $(11.81,15.05)$ & - & - & Model at $0 \mathrm{~h}$ \\
\hline $\mathrm{K} 24 \mathrm{~m}$ & 150 & - & $(37.65,14.72)$ & 1.047 & 100 & Model at $24 \mathrm{~h}$ \\
\hline
\end{tabular}

The observed plumes of toluene at $24 \mathrm{~h}$ are shown in Figure $2 \mathrm{~b}$. The toluene peak depicted in $2 \mathrm{c}$ slightly precedes the $\mathrm{KCl}$ peak in the longitudinal direction, whereas in the transverse direction the peak distances are similar. The calculated mass center of the toluene plumes was located at $(37.25,14.35)$, with an average linear velocity $\left(v_{x}\right)$ of $1.052 \mathrm{~cm} / \mathrm{h}$, similar to that of the $\mathrm{KCl}$ plume. This suggests that there was no retardation during the transport of toluene, even though the peak of toluene appeared to be slightly ahead of the peak of $\mathrm{KCl}$. In contrast, the plume area of toluene was smaller than that of $\mathrm{KCl}$. The mass of toluene was reduced due to the sorption of toluene onto the sandy soil during transport. The mass recovery of toluene was $60.2 \%$, indicating about $40 \%$ toluene attenuation. Figure $3 \mathrm{a}, \mathrm{b}$ shows a cross-section of the contaminant plume on the $\mathrm{x}$ and $\mathrm{y}$ axes, respectively. The peaks of the $\mathrm{KCl}$ and toluene plumes appear at the same relative concentration, whereas decreases in toluene concentrations were observed significantly at the edges of plumes. The attenuation of BTC without retardation could be simulated using first-order irreversible sorption, but these simulated BTCs could not explain the significant reduction in the solute concentration at the edge of plume [27-29]. This behavior is very different from what was reported in previous studies. The retarded transport observed in the several field tests did not occur in this study [33]. The significant concentration reduction at the boundary, rather than at the peak, is far from the characteristics of irreversible adsorption observed in the one-dimensional column test [27-29].
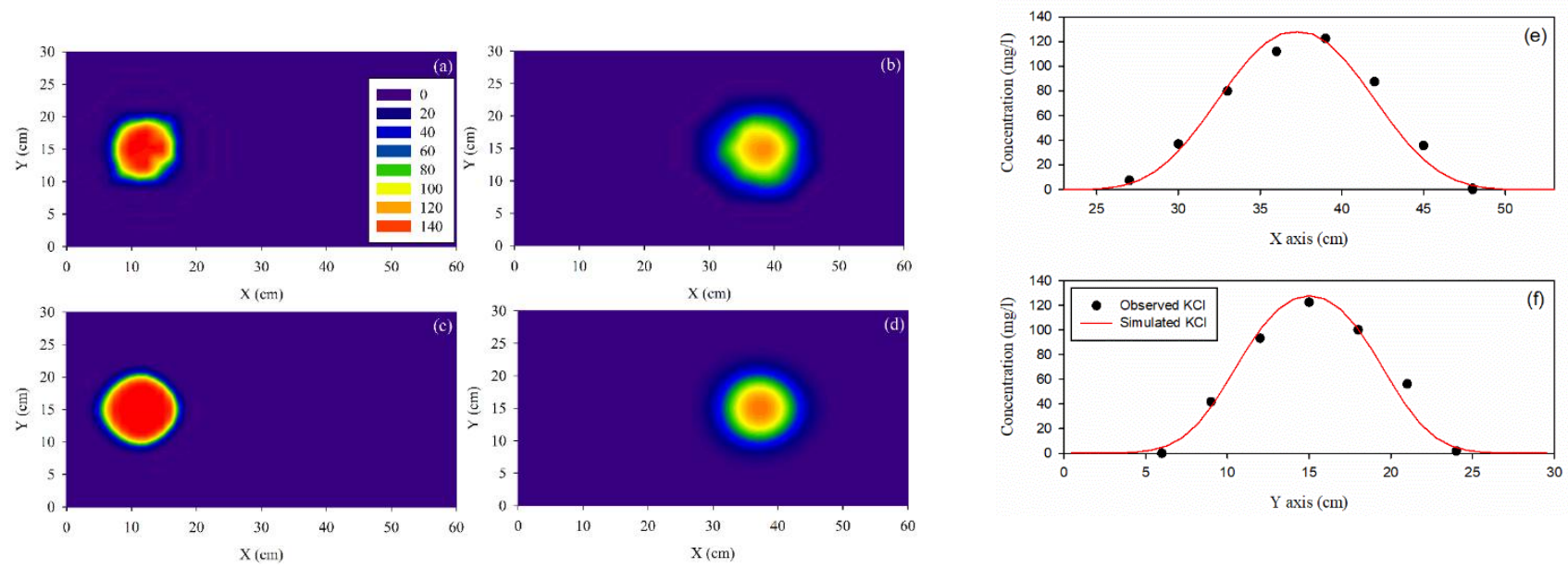

Figure 3. $\mathrm{KCl}$ plumes (unit of contour $\mathrm{mg} / \mathrm{L}$ ) observed (a) at the initial stage, (b) after $24 \mathrm{~h}$; the simulated plumes (c) at the initial stage and (d) after $24 \mathrm{~h}$; and (e,f) cross-section of concentration along the $\mathrm{x}$ - and $\mathrm{y}$ - axes after $24 \mathrm{~h}$.

\subsection{Modeling Advection and Dispersion in Two-Dimensional Sand Box}

Numerical modeling for the two-dimensional water flow is depicted in Figure S1. Figure S1a,b shows equipotential lines during tracer injection and after tracer injection. During the tracer injection, the equipotential lines spread radially from the injection point. After tracer injection, the equipotential lines were parallel to the y axis and the flow in the $\mathrm{x}$ axis prevailed. The two-dimensional transport of $\mathrm{KCl}$ was modeled numerically, and the 
dispersivity was obtained through comparison with the observed results. The optimized $\mathrm{KCl}$ plume is shown in Figure 3. The mass centers of the observed and the modeled $\mathrm{KCl}$ plumes were similarly calculated at 0 and $24 \mathrm{~h}$. This indicates the successful simulation of the advective process. The moment analysis for the modeled plume showed that the average linear velocity $(1.047 \mathrm{~cm} / \mathrm{h})$ is similar to that of the observed plume $(1.067 \mathrm{~cm} / \mathrm{h})$. The dispersivity of $\mathrm{KCl}$ was estimated, with $\alpha_{\mathrm{L}}=0.141 \mathrm{~cm}, \alpha_{\mathrm{T}} / \alpha_{\mathrm{L}}=0.62$. The obtained dispersivity was used as the dispersivity of toluene.

\subsection{Appropriate Model of Toluene Sorption during Transport through Saturated Sand \\ 3.3.1. Suitability of Linear Equilibrium and Nonequilibrium Irreversible Models}

In the previous field-scale injection test for organic contaminant, a different degree of retarded transport was observed with respect to their hydrophobicity. This retardation could be explained by means of an equilibrium approach, using a linear sorption isotherm normalized using the soil organic carbon fraction. Several studies conducted on laboratory-scale tests have reported the retardation of organic contaminants using oneor two-dimensional experiment [30-32]. Several studies reported only the attenuation of organic contaminants without retardation, thus describing an irreversible type of sorption kinetics. Here, we tried to describe the sorption of a toluene plume using these sorption models. Using the parameter optimization algorithm, the error functions of the parameter domains are presented in Figure 4. The optimized parameters are tabulated in Table 4, and the optimized simulations of toluene plumes using each sorption model are compared with the observed results in Figure 5. The cross-sections of the toluene plumes along with the longitudinal and transverse directions are compared in Figure 6.
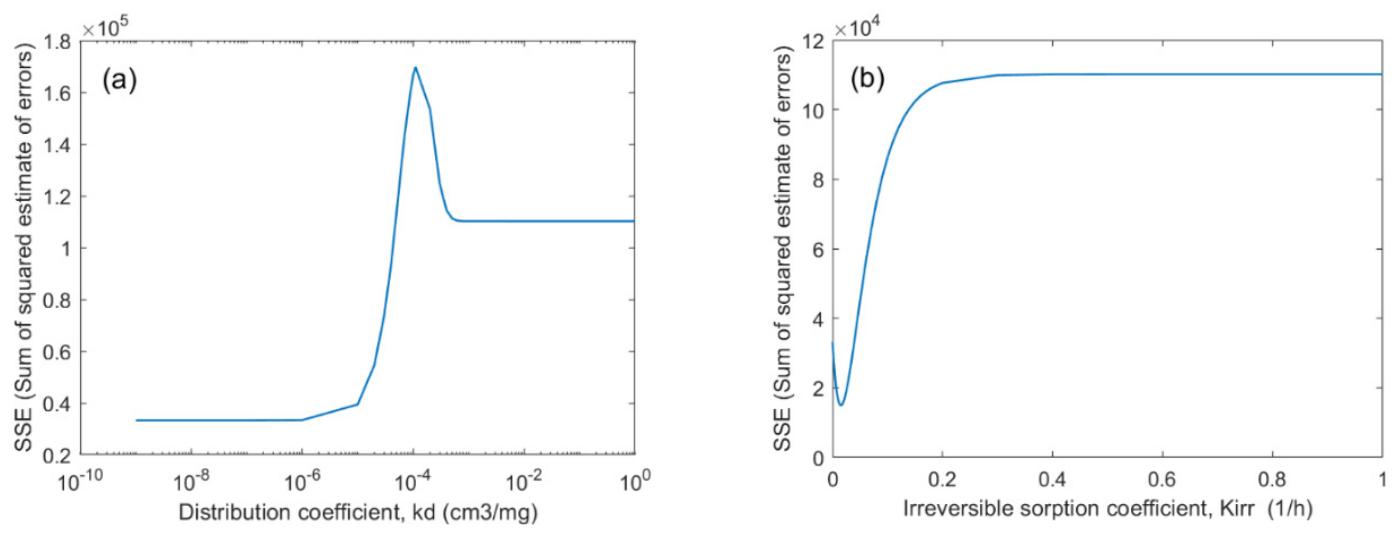

Figure 4. Goodness of fit in the simulations of toluene transport using (a) the linear isotherm model, (b) the kinetic-irreversible model. The curve shows the change in SSE (sum of squared error) according to the value of the adsorption parameter.

Table 4. Sorption parameters estimated by fitting sorption models to the observed plume of toluene.

\begin{tabular}{|c|c|c|c|c|c|c|c|c|c|}
\hline \multirow[b]{2}{*}{ Model } & \multicolumn{6}{|c|}{ Parameter } & \multirow[b]{2}{*}{ SSE } & \multirow[b]{2}{*}{$R^{2}$} & \multirow{2}{*}{$\begin{array}{c}\text { Mass } \\
\text { Recovery } \\
(\%)\end{array}$} \\
\hline & $\begin{array}{c}\mathbf{k}_{\text {irr }} \\
(\mathbf{1} / \mathrm{h})\end{array}$ & $\begin{array}{c}\mathrm{K}_{d} \\
\left(\mathrm{~cm}^{3} / \mathrm{mg}\right)\end{array}$ & $\begin{array}{c}\mathrm{k}_{f} \\
\left(\mathrm{~cm}^{3} / \mathrm{mg}\right)^{a}\end{array}$ & $\begin{array}{c}\mathbf{a} \\
(-)\end{array}$ & $\begin{array}{c}\mathbf{k}_{l} \\
\left(\mathrm{~cm}^{3} / \mathrm{mg}\right)\end{array}$ & $\begin{array}{c}\mathrm{b} \\
(\mathrm{mg} / \mathrm{mg})\end{array}$ & & & \\
\hline Kinetic-irr & $1.5 \times 10^{-2}$ & - & - & - & - & - & $1.50 \times 10^{4}$ & 0.82 & 69.86 \\
\hline Linear & - & $1.0 \times 10^{-8}$ & - & - & - & - & $3.33 \times 10^{4}$ & 0.60 & 99.99 \\
\hline Freundlich & - & - & $7.76 \times 10^{-4}$ & $9.1 \times 10^{-4}$ & - & - & $2.25 \times 10^{4}$ & 0.73 & 73.73 \\
\hline Langmuir & - & - & - & - & $2.48 \times 10^{3}$ & $5.72 \times 10^{-4}$ & $1.20 \times 10^{4}$ & 0.86 & 66.64 \\
\hline
\end{tabular}



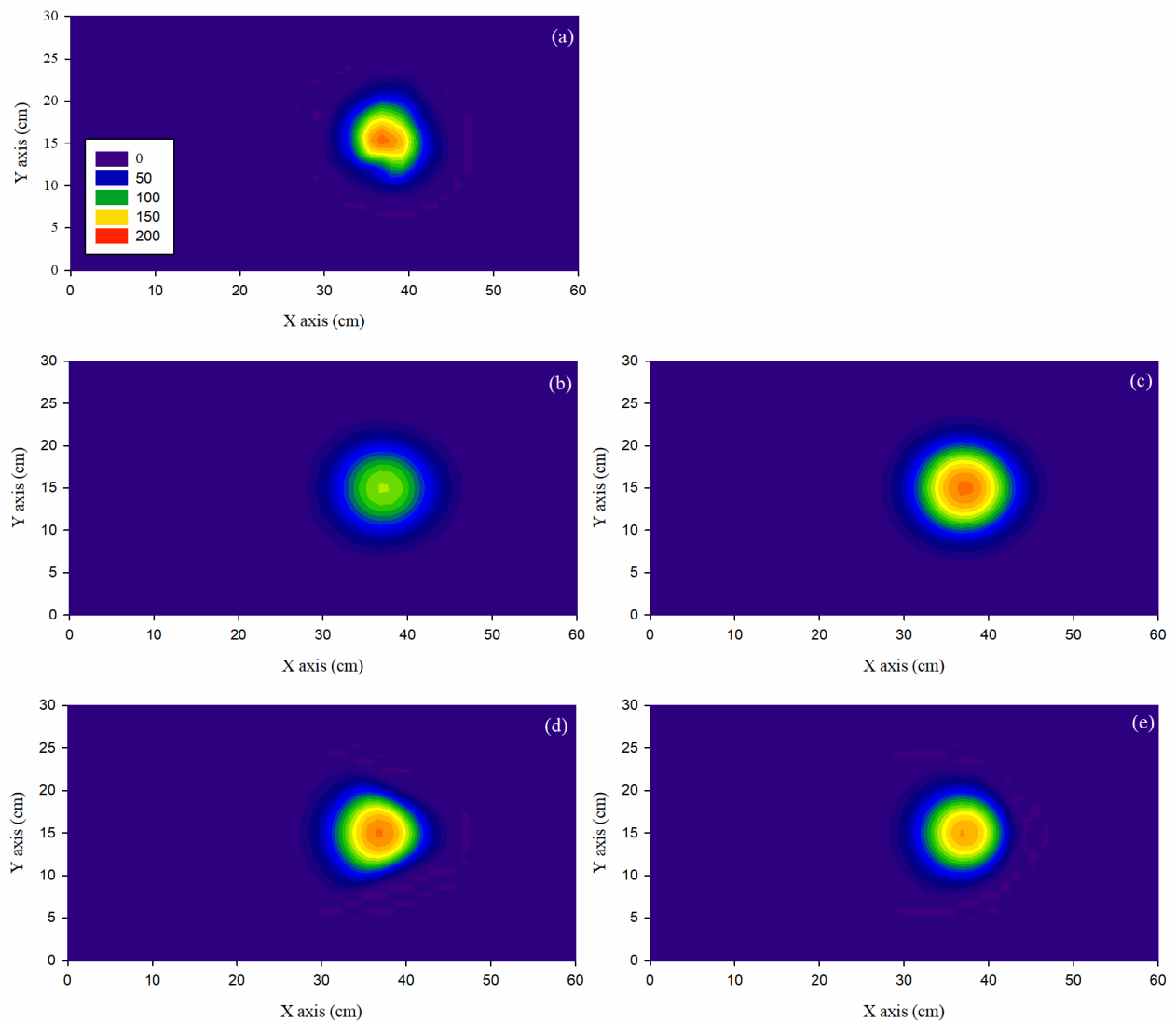

Figure 5. (a) Observed toluene plume, and the simulated using various sorption models (unit of contour mg/L): (b) kinetic-irreversible, (c) linear isotherm, (d) Freundlich isotherm and (e) Langmuir isotherm models.
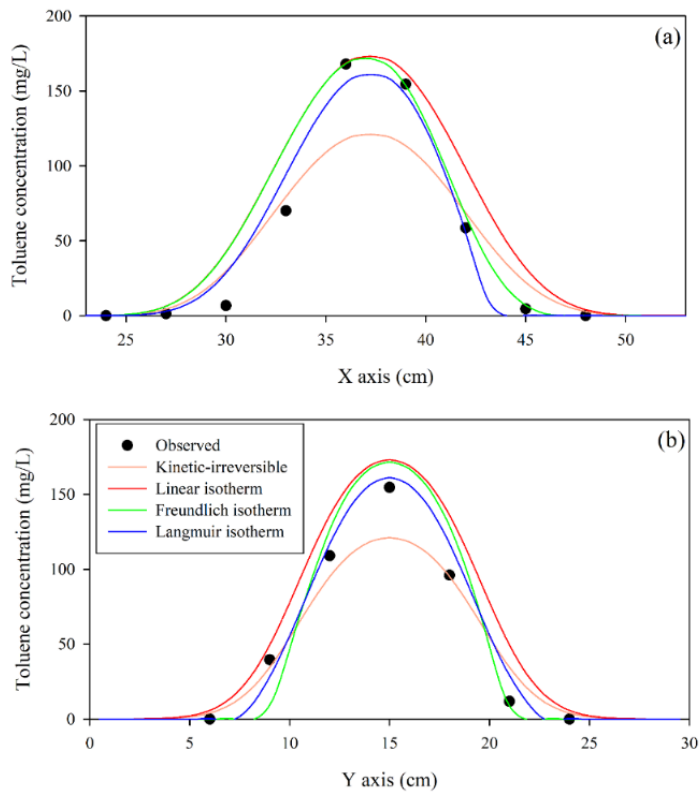

Figure 6. Concentration distribution of toluene plume: (a) $x$-axis direction $(y=15 \mathrm{~cm})$; $(\mathbf{b}) \mathrm{y}$-axis direction $(x=39 \mathrm{~cm})$.

We estimated the optimal sorption parameters of linear sorption isotherm, $K_{d}$, and kinetic irreversible sorption rate, $k_{i r r}$. The error function in the parameter domain of $K_{d}$ is shown in Figure 4a. The local minimum is not unique, so the error function minimized at 
below $1.0 \times 10^{-8}\left(\mathrm{~cm}^{3} / \mathrm{mg}\right)$. At $K_{d}=1.0 \times 10^{-8} \mathrm{~cm}^{3} / \mathrm{mg}$, the simulated toluene plume was not attenuated at all (mass recovery $=99.99 \%$ ), and the optimization results could not explain the observations $\left(R^{2}=0.60\right)$. The comparison of the observed plume with the simulation also showed significant discrepancies (Figure $5 c$ ). This suggests that the linear sorption isotherms may not be adequate for the description of plume transport in the laboratory, even though it may be able to could describe the retardation during field-scale transport. This is a different result from the previous studies that have explained the behavior of organic pollution in a field conditions using with a linear sorption isotherm. This difference is thought to be caused by the difference between the organic matter content and the degree of contamination in the soil used in the experiment. The heterogeneous soil in field conditions contains clay and levels of natural organic matters that are significantly higher than $\mathrm{f}_{\mathrm{oc}}$. These soil conditions correspond corresponds to the isotherm conditions, with a large maximum adsorption amount. This, so that it can be interpreted as a situation in which soil was exposed to pollution at a level lower than the capacity of the soil. have. In this case, it is effective to explain the behavior of organic pollution through linear adsorption characteristics. On the contrary, in this experiment, soil with a minimal content of organic matter content was used through washing, which could that it can be interpreted as a situation in which the soil was exposed to a relatively high concentration of pollution due to its low sorption capacity. In such an environment, the equilibrium state can appear to be a phenomenon in which the pollutants are irreversibly removed. For this reason, it can be theorized that the characteristics of irreversible adsorption were observed in a one-dimensional experiment in which a high concentration of contamination was imposed, and that the same phenomenon can be explained by nonlinear adsorption with a low maximum adsorption amount.

The error function in the parameter domain of $k_{\text {irr }}$ is shown in Figure $4 \mathrm{~b}$. The unique local minimum of error function was found at $k_{\text {irr }}=1.5 \times 10^{-2} / \mathrm{h}$. The simulated plume showed a high coefficient of determination $\left(R^{2}=0.82\right)$ and the mass recovery $(69.86 \%)$ was very similar to that observed for toluene $(60.2 \%)$. Because the kinetic-irreversible model cannot induce retardation, the observe toluene plume was not retarded; the measured plume and the modeled were located in a similar position (Figure 5b). It is possible to explain the attenuation of toluene using irreversible sorption, as reported in some onedimensional column studies. However, the peak concentration of the modeled plume was lower than that of the observed plume, and the modeled plume area was larger than the observed area (Figure 6).

\subsubsection{Suitability of Non-Linear Equilibrium Models}

The above results indicate that the two most commonly used models to describe the sorption of organic contaminants are insufficient to describe laboratory-scale twodimensional transport characteristics. In the laboratory experiments, no retardation was observed, and the irreversible adsorption was explained by excessive contaminant removal. Conversely, we expected that the model of the strong adsorption of limited amounts of organic pollutants would be able to explain the adsorption characteristics of organic contaminants during transportation. These properties are well known as the properties of the nonlinear sorption isotherm. Therefore, the following analyses were conducted to determine whether the nonlinear equilibrium adsorption model is suitable for the description of the adsorption characteristics during the transport of two-dimensional toluene.

To select the type of sorption that is able to best represent the fate of toluene, two nonlinear equilibrium models (Freundlich isotherm and Langmuir isotherm) were applied to simulate toluene transport. We estimated the optimal sorption parameters of the Freundlich sorption isotherm, $K_{f}$ and $\alpha$. The error function in the parameter domain of $K_{f}$ and $\alpha$ is shown in Figure 7a. The optimization the algorithm was carried out by repeatedly reducing the parameter domain to find the best parameter set (Figure S2). The surface of the 
error function was plotted on the parameter space with sufficient range for global optimization. The error function was minimized at $K_{f}=7.64 \times 10^{-4}\left(\mathrm{~cm}^{3} / \mathrm{mg}\right), \alpha=9.10 \times 10^{-4}(-)$ (Table 3).
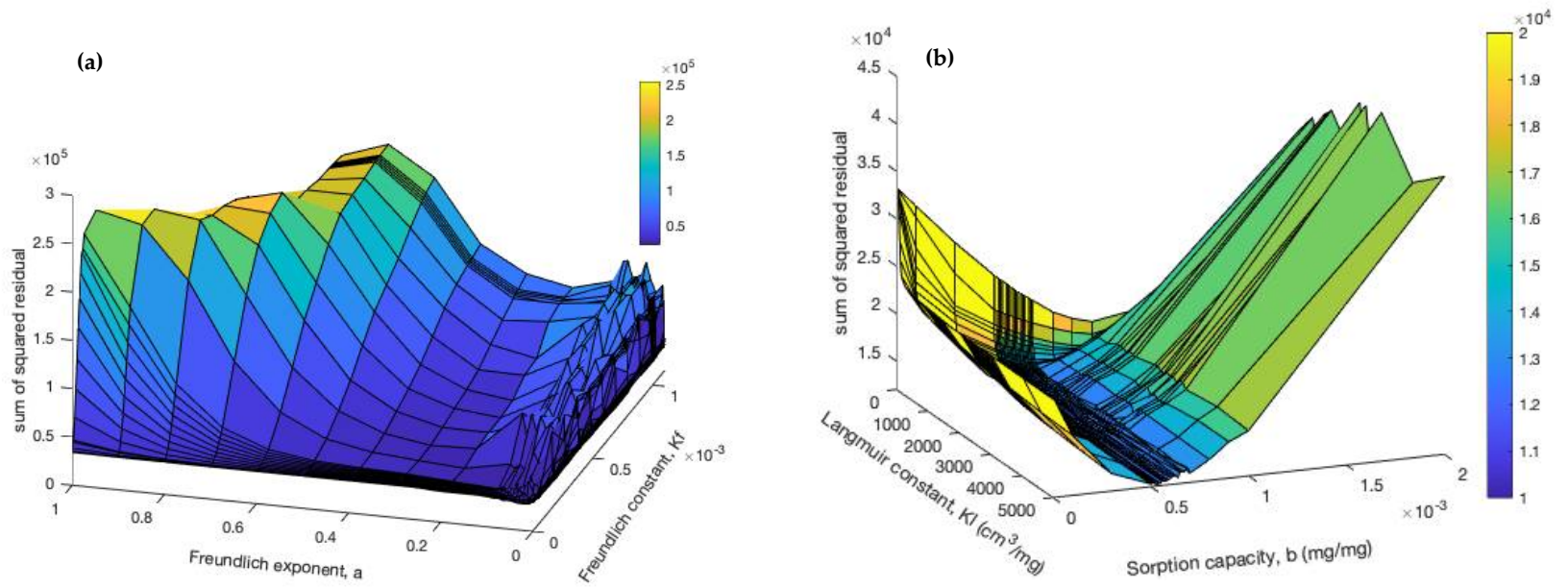

Figure 7. Goodness of fit in the simulation of toluene transport: (a) Freundlich isotherm model; (b) Langmuir isotherm model.

The plume simulated using the Freundlich isotherm models showed similar trends in terms of plume locations and areas with the observed results, and the sharpening of the solute front was also similarly explained (Figure 6). However, the mass recovery (73.73\%) was evaluated higher than the observed results $(60.2 \%)$ and the parameter optimization results were not able to explain the observations sufficiently $\left(R^{2}=0.73\right)$.

Finally, we estimated the optimal sorption parameters of the Langmuir sorption isotherm, $K_{l}$ and $\beta$. The error function in the parameter domain of $K_{l}$ and $\beta$ is shown in Figure $7 \mathrm{~b}$. The optimization algorithm was carried out by repeatedly reducing the parameter domain to find the best parameter set (Figure S3). The change in the error function was sensitive to the sorption capacity $(\beta)$, resulting in a valley with low error at $\beta=5.0 \times 10^{-3}$ to $6.0 \times 10^{-3}$ on the surface of the error function. This indicates that the limited amount of the sorption site it is the most sensitive property in controlling the fate of toluene during transport. The error function was minimized at $K_{l}=2.48 \times 10^{3}\left(\mathrm{~cm}^{3} / \mathrm{mg}\right)$ and $\beta=5.72 \times 10^{-4}(\mathrm{mg} / \mathrm{mg})$ (Table 3). The Langmuir isotherm model explained the transport of toluene with a high goodness of fit $\left(R^{2}=0.86\right)$ and showed a similar plume location, shape and mass reduction (mass recovery $=66.64 \%$ ) to the observed results. The simulated plume was also able to explain the sharpening of the solute front (Figure 6).

In Figure 6, the observed distribution of the toluene plume and the distribution simulated using optimized sorption parameters are compared using cross-sectional views in longitudinal and transverse directions. The irreversible kinetic sorption model showed lower peak concentrations, whereas the linear isotherm model showed higher distributions than the observed concentrations. The Freundlich isotherm and the Langmuir isotherm showed lower concentration distributions at the edges of the contaminant plume than the irreversible kinetic sorption model and the linear isotherm model. Among these models, the Langmuir isotherm model showed the curve that was closest to the observed values.

The smaller size of the toluene plume compared to the size of the conservative tracer plume indicates that the sorption is faster at the flange of the plume. This indicates that in the distribution of toluene concentration by dispersion, rapid sorption occurs at the flange (low concentration) and less sorption occurs at the center (high concentration). In other words, the quartz sand used in this study places a limitation on the sorption capacity of toluene. Barry et al. (2002) reported that the Langmuir model is applicable to cases in which sorption is limited to a finite capacity that is being represented [42]. Many studies on the sorption of various dissolved organic compounds onto the soil have reported that the Freundlich and linear models are more suitable than the Langmuir model [43-45]. This is because all models are similar to the linear model at low concentrations [46]. Ball and 
Roberts (1991) reported that nonlinear isotherms (Langmuir and Freundlich models) of tetrachloroethene (PCE) and 1,2,4,5-tetrachlorobenzene (TeCBz) on sandy aquifer solids fit the entire range of data much better than the simple linear relationship did [47]. At the low concentrations $(<50 \mathrm{mg} / \mathrm{L})$ relevant to the rate studies [47,48] and field experiments [49] the isotherm data appeared to be more linear. To simulate the transport of high-concentration hydrocarbons, as in this study, the use of models with limited sorption capacity should be considered.

The above results indicate that the nonlinear adsorption characteristics were certainly valid for explaining the transport of organic contaminants. The sorption isotherms for the optimized parameters, presented in Figure 8, show that the two nonlinear isotherms have a limited adsorption capacity to solids. This might be related to the soil conditions, which had a low organic content. The sandy soil used in this experiment was mainly composed of quartz, and because organic matter is removed by washing, it is considered to have relatively fewer adsorption sites than general soil. Therefore, the nonlinear adsorption characteristics with limited adsorption sites could explain the experimental results well. The Freundlich isotherm is a model in which the amount of adsorption increases nonlinearly with an increasing liquid concentration. However, it was expressed as having a limited adsorption site in the optimized simulation. This seems to be because the optimized Freundlich exponent, $\mathrm{b}(-)$, was too small (value $=0.00091$ ), and so it converged to the zero-order reaction.
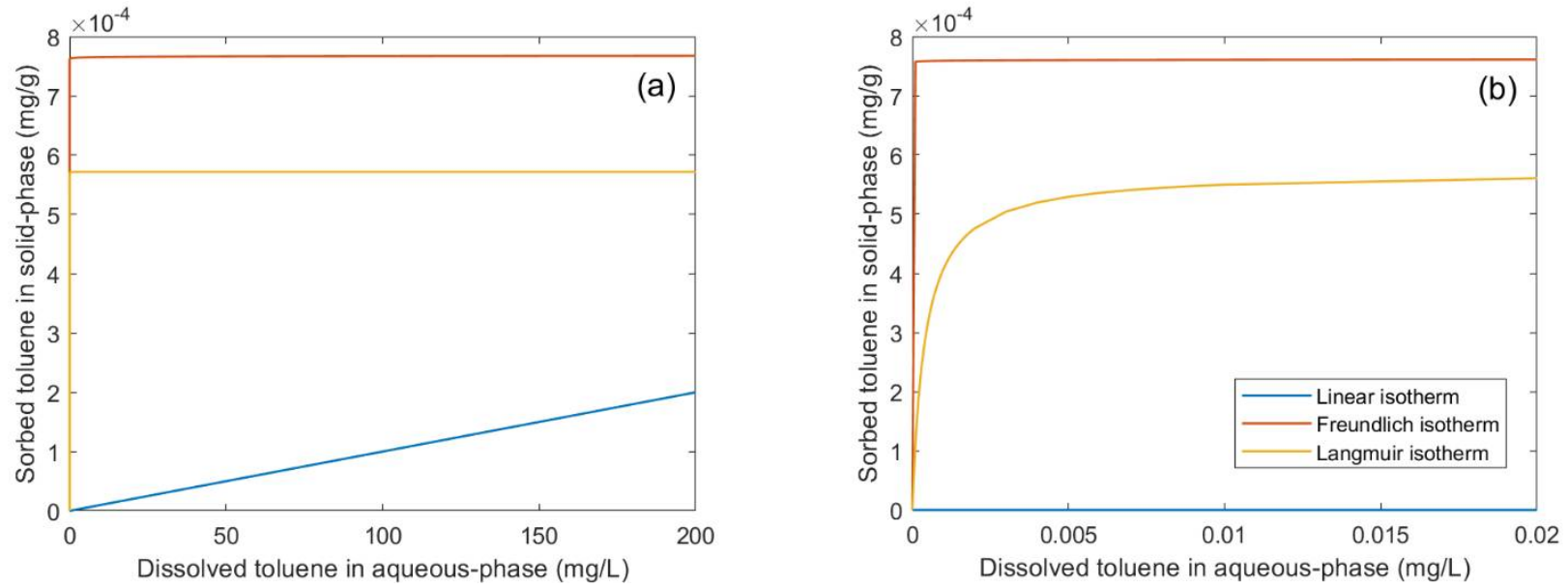

Figure 8. Estimated sorption isotherm curve in the simulation of toluene transport: (a) toluene concentration $=0 \sim 200 \mathrm{mg} / \mathrm{L}$; (b) toluene concentration $=0 \sim 0.02 \mathrm{mg} / \mathrm{L}$.

The Langmuir isotherm, shown in Figure 8b, indicates that the soil toluene adsorption capacity was already saturated at toluene concentrations above $0.005 \mathrm{mg} / \mathrm{L}$. It can be inferred that the reactive site of the soil surface with a small capacity is easily saturated by a low concentration of the contaminant through hydrophobic adsorption, and no further adsorption proceeds. This reduces the concentration of organic pollutants that are more pronounced in the areas with low concentrations, such as in the vicinity of a plume. This may be attributed to the decrease in the size of the toluene plume during transport.

\section{Conclusions}

The transport of an organic contaminant through sandy material was investigated using an areal two-dimensional saturated aquifer model. In the toluene transport experiment, the toluene plume showed a decrease in mass, as well as plume size. The shape of the toluene plume could be explained using the nonlinear sorption model, especially the Langmuir isotherm model. We conclude that for the retarded and attenuated transport of organic pollutants, it is appropriate to use a transport model that considers nonlinear isothermal adsorption. The results of this study also suggest a methodology for evaluating 
the fate and transport characteristics of organic pollutants in aquifers. The adsorption of organic pollutants - which is sensitively affected by organic matter contained in small amounts in the soil-is difficult to distinguish from irreversible adsorption characteristics through one-dimensional laboratory experiments. In this case, two-dimensional transport experiments may be a promising alternative. In particular, two-dimensional experiments are more appropriate than one-dimensional column experiments in identifying the adsorption characteristics that occur during transport in saturated aquifers. The short pulse injection in the 2D sand box was able to monitor the transport, dispersion and attenuation of contaminants at the margin, as well as the center of the plume. Therefore this study can supply an experimental approach to assessing the natural attenuation of organic contaminants in a subsurface environment which has a high contamination level in heterogeneous media, affected by various (a)biotic processes.

Supplementary Materials: The following are available online at https:/ / www.mdpi.com/article/10 .3390 /w13111557/s1, Figure S1: Result of flow modeling using MODFLOW code (unit of contour, $\mathrm{cm})$ : (a) injection time $\left(0<\mathrm{t}<\mathrm{t}_{0}\right)$, (b) after injection $\left(\mathrm{t}>\mathrm{t}_{0}\right)$, Figure S2: Modeling procedure for the Freundlich sorption isotherm (Freundlich constant $\left(K_{f}\right)$, Freundlich exponent $(a)$ ): (a) $K_{f}=1.0 \times 10^{-6}$ $\sim 1.1 \times 10^{-3} ; a=1.0 \times 10^{-8} \sim 1.0 ;(b) K_{f}=1.0 \times 10^{-5} \sim 2.0 \times 10^{-4} ; a=1.0 \times 10^{-3} \sim 1.0 \times 10^{-1}$. Figure S3: Modeling procedure for the Langmuir sorption isotherm (Langmuir constant $\left(K_{l}\right)$; total concentration of sorption sites available $(b)$ ): (a) $K_{l}=1.0 \sim 1.0 \times 10^{4} ; b=1.0 \times 10^{-5} \sim 1.0$; (b) $\mathrm{SSR}=1.2 \times 10^{4} \sim 1.25 \times 10^{4}$, (c) $K_{l}=2.35 \times 10^{3} \sim 2.25 \times 10^{3} ; b=5.7 \times 10^{-4} \sim 5.9 \times 10^{-4}$.

Author Contributions: Conceptualization, S.L. and J.-W.C.; methodology, S.-G.L.; software, S.-G.L.; validation, S.L.; formal analysis, S.L.; investigation, S.-G.L.; writing-original draft preparation, S.-G.L.; writing-review and editing, J.-W.C.; supervision, J.-W.C.; project administration, S.L. All authors have read and agreed to the published version of the manuscript. Please turn to the CRediT taxonomy for the explanation of terms.

Funding: This research was funded by Ministry of Environment (MOE), grant number 2018002470002 and Korea Ministry of Science and ICT (grant number NRF-2017R1C1B3009500).

Data Availability Statement: Not applicable.

Acknowledgments: This work was supported by the Korea Environment Industry Institute (KEITI) through the Underground environmental pollution risk management technology development business Program, funded by the Ministry of Environment (MOE) (grant number: 2018002470002), and the National Research Foundation of Korea (NRF) grant funded by the Korea Ministry of Science and ICT (grant number NRF-2017R1C1B3009500).

Conflicts of Interest: The authors declare no conflict of interest.

\section{References}

1. Kao, C.M.; Wang, C.C. Control of BTEX migration by intrinsic bioremediation at a gasoline spill site. Water Res. 2000, 34, 3413-3423. [CrossRef]

2. An, Y.-J. Toxicity of benzene, toluene, ethylbenzene, and xylene (BTEX) mixtures to Sorghum bicolor and Cucumis sativus. Bull. Environ. Contam. Toxicol. 2004, 72, 1006-1011. [CrossRef]

3. Liu, F.F.; Peng, C.; Ng, J.C. BTEX in vitro exposure tool using human lung cells: Trips and gains. Chemosphere 2015, 128, 321-326. [CrossRef]

4. Farhadian, M.; Vachelard, C.; Duchez, D.; Larroche, C. In situ bioremediation of monoaromatic pollutants in groundwater: A review. Bioresour. Technol. 2008, 99, 5296-5308. [CrossRef] [PubMed]

5. US Environmental Protection Agency Washington. Edition of the Drinking Water Standards and Health Advisories. Available online: https://www.epa.gov/sites/production/files/2018-03/documents/dwtable2018.pdf (accessed on 1 February 2021).

6. Tran, T.D.; Nguyen, T.X.; Nguyen, H.T.T.; Vo, H.T.L.; Nghiem, D.T.; Le, T.H.; Dao, D.S.; Nguyen, N.V. Seasonal Variation, Sources, and Health Risk Assessment of Indoor/Outdoor BTEX at Nursery Schools in Hanoi, Vietnam. Water Air Soil Pollut. $2020,231$. [CrossRef]

7. Tohidian, E.; Dehban, A.; Ashtiani, F.Z.; Kargari, A. Fabrication and characterization of a cross-linked two-layer polyetherimide solvent-resistant ultrafiltration (SRUF) membrane for separation of toluene-water mixture. Chem. Eng. Res. Des. 2021, 168, 59-70. [CrossRef]

8. Lakhouit, A.; Cabral, A.R.; Cabana, H. Two Novel Biofilters to Remove Volatile Organic Compounds Emitted by Landfill Sites. Water Air Soil Pollut. 2016, 227. [CrossRef] 
9. Jun, T.H.; Kim, M.J.; Kim, S.; Jung, Y.H.; Moon, H.R.; Kim, K.S. Evaluation of Activated Carbon-Coated Electrode in Electrostatic Precipitator and Its Regeneration for Volatile Organic Compounds Removal. Water Air Soil Pollut. 2017, 228. [CrossRef]

10. Li, Y.; Shankar, V.S.B.; Yalamanchi, K.K.; Badra, J.; Nicolle, A.; Sarathy, S.M. Understanding the blending octane behaviour of unsaturated hydrocarbons: A case study of C-4 molecules and comparison with toluene. Fuel 2020, 275. [CrossRef]

11. Aminnaji, M.; Golfier, F.; Niasar, V.J.; Babaei, M. Interplay of biofilm growth, NAPL biodegradation and micro-scale heterogeneity in natural attenuation of aquifers delineated by pore-network modelling. Adv. Water Resour. 2020, 145. [CrossRef]

12. Powers, S.E.; Hunt, C.S.; Heermann, S.E.; Corseuil, H.X.; Rice, D.; Alvarez, P.J. The transport and fate of ethanol and BTEX in groundwater contaminated by gasohol. Crit. Rev. Environ. Sci. Technol. 2001, 31, 79-123. [CrossRef]

13. ARAL; Aral, M. Advances in Groundwater Pollution Control and Remediation; Springer Science \& Business Media: Berlin, Germany, 2013; Volume 9.

14. Fetter, C.W. Contaminant Hydrogeology; Waveland Press, Inc.: Long Grove, IL, USA, 2008; Volume 1, pp. $120-168$.

15. Chrysikopoulos, C.V.; Kitanidis, P.K.; Roberts, P.V. Analysis of one-dimensional solute transport through porous-media with spatially-variable retardation factor. Water Resour. Res. 1990, 26, 437-446. [CrossRef]

16. Chrysikopoulos, C.V.; Kitanidis, P.K.; Roberts, P.V. Macrodispersion of sorbing solutes in heterogeneous porous formations with spatially periodic retardation factor and velocity-field. Water Resour. Res. 1992, 28, 1517-1529. [CrossRef]

17. Chrysikopoulos, C.V.; Kitanidis, P.K.; Roberts, P.V. Generalized taylor-aris moment analysis of the transport of sorbing solutes through porous-media with spatially periodic retardation factor. Transp. Porous Media 1992, 7, 163-185. [CrossRef]

18. Cheng, J.; Ye, Q.; Lu, Z.; Zhang, J.; Zeng, L.; Parikh, S.J.; Ma, W.; Tang, C.; Xu, J.; He, Y. Quantification of the sorption of organic pollutants to minerals via an improved mathematical model accounting for associations between minerals and soil organic matter. Environ. Pollut. 2021, 280, 116991. [CrossRef] [PubMed]

19. Wang, W.; Zhang, X.; Zhang, Y.H.; Mi, X.; Wang, R.; Shi, H.L.; Li, C.L.; Du, Z.W.; Qiao, Y.M. Adsorption of emerging sodium p-perfluorous nonenoxybenzene sulfonate (OBS) onto soils: Kinetics, isotherms and mechanisms. Pedosphere 2021, 31, 596-605. [CrossRef]

20. Liu, Y.J.; Qi, F.J.; Fang, C.; Naidu, R.; Duan, L.C.; Dharmarajan, R.; Annamalai, P. The effects of soil properties and co-contaminants on sorption of perfluorooctane sulfonate (PFOS) in contrasting soils. Environ. Technol. Innov. 2020, 19. [CrossRef]

21. Foo, K.Y.; Hameed, B.H. Insights into the modeling of adsorption isotherm systems. Biochem. Eng. J. 2010, 156, 2-10. [CrossRef]

22. Maamoun, I.; Eljamal, R.; Falyouna, O.; Bensaida, K.; Sugihara, Y.; Eljamal, O. Insights into kinetics, isotherms and thermodynamics of phosphorus sorption onto nanoscale zero-valent iron. J. Mol. Liq. 2021, 328. [CrossRef]

23. Vilcaez, J. Reactive transport modeling of produced water disposal into dolomite saline aquifers: Controls of barium transport. J. Contam. Hydrol. 2020, 233. [CrossRef]

24. Gharoon, N.; Pagilla, K.R. Critical review of effluent dissolved organic nitrogen removal by soil/aquifer-based treatment systems. Chemosphere 2021, 269. [CrossRef]

25. Wang, Y.; Khan, N.; Huang, D.; Carroll, K.C.; Brusseau, M.L. Transport of PFOS in aquifer sediment: Transport behavior and a distributed-sorption model. Sci. Total Environ. 2021, 779, 146444. [CrossRef] [PubMed]

26. Banzhaf, S.; Hebig, K.H. Use of column experiments to investigate the fate of organic micropollutants-A review. Hydrol. Earth Syst. Sci. 2016, 20, 3719-3737. [CrossRef]

27. Chung, S.G.; Kim, D.J.; Choi, J.W.; Lee, S.H. Processes Aaffecting Fate of Toluene During Transport Through Quartz Sand. Environ. Prog. Sustain. Energy 2012, 31, 318-324. [CrossRef]

28. Kim, S.B.; Kim, D.J.; Yun, S.T. Attenuation of aqueous benzene in soils under saturated flow conditions. Environ. Technol. 2006, 27, 33-40. [CrossRef]

29. Kim, D.J.; Choi, N.C.; Kim, S.B. Quantification of irreversible benzene sorption in sandy materials. Hydrol. Processes 2004, 18, 3229-3234. [CrossRef]

30. Chrysikopoulos, C.V.; Lee, K.Y.; Harmon, T.C. Dissolution of a well-defined trichloroethylene pool in saturated porous media: Experimental design and aquifer characterization. Water Resour. Res. 2000, 36, 1687-1696. [CrossRef]

31. Lee, K.Y.; Chrysikopoulos, C.V. Dissolution of a well-defined trichloroethylene pool in saturated porous media: Experimental results and model simulations. Water Res. 2002, 36, 3911-3918. [CrossRef]

32. Lee, K.Y.; Chrysikopoulos, C.V. Dissolution of a multicomponent DNAPL pool in an experimental aquifer. J. Hazard. Mater. 2006, 128, 218-226. [CrossRef]

33. Mackay, D.M.; Roberts, P.V.; Cherry, J.A. Transport of organic contaminants in groundwater. Environ. Sci. Technol. 1985, 19, 384-392. [CrossRef] [PubMed]

34. Spurlock, F.C.; Huang, K.; Vangenuchten, M.T. Isotherm nonlinearity and nonequilibrium sorption effects on transport of fenuron and monuron in soil columns. Environ. Sci. Technol. 1995, 29, 1000-1007. [CrossRef] [PubMed]

35. Hu, M.Q.; Brusseau, M.L. Coupled effects of nonlinear, rate-limited sorption and biodegradation on transport of 2.4dichlorophenoxyacetic acid in soil. Environ. Toxicol. Chem. 1998, 17, 1673-1680. [CrossRef]

36. Lee, S.-G.; Kim, M.-H.; Kim, D.-J.; Lee, Y.-J. Fate and transport of zinc in a sand tank model: Monitoring of 2-D plume using TDR method. Environ. Earth Sci. 2013, 72, 1-9. [CrossRef]

37. Freyberg, D.L. A natural gradient experiment on solute transport in a sand aquifer: 2. spatial moments and the advection and dispersion of nonreactive tracers. Water Resour. Res. 1986, 22, 2031-2046. [CrossRef] 
38. McDonald, M.G.; Harbaugh, A.W. A Modular Three-Dimensional Finite-Difference Ground-Water Flow Model; U.S. Geological Survey, Techniques of Water-Resources Investigations: Denver, Colorado, 1988; Volume Book 6.

39. Choi, J.W.; Ha, H.C.; Kim, S.B.; Kim, D.J. Analysis of benzene transport in a two-dimensional aquifer model. Hydrol. Processes 2005, 19, 2481-2489. [CrossRef]

40. Zheng, C.; Wang, P.P. MT3DMS: A Modular Three-Dimensional Multispecies Transport Model for Simulation of Advection, Dispersion, and Chemical Reactions of Contaminants in Groundwater Systems; Documentation and User's Guide; University of Alabama: Tuscaloosa, AL, USA, 1999.

41. Kang, S.Y.; Lee, S.G.; Kim, D.J.; Shin, J.; Kim, J.; Lee, S.; Choi, J.W. Comparison of optimization algorithms for modeling of Haldane-type growth kinetics during phenol and benzene degradation. Biochem. Eng. J. 2016, 106, 118-124. [CrossRef]

42. Barry, D.A.; Prommer, H.; Miller, C.T.; Engesgaard, P.; Brun, A.; Zheng, C. Modelling the fate of oxidisable organic contaminants in groundwater. Adv. Water Resour. 2002, 25, 945-983. [CrossRef]

43. Rao, B.H.; Swaminathan, R.; Asolekar, S.R. Washing of marine coastal sand in a batch reactor: Sorption and desorption of BTEX. J. Air Waste Manag. Assoc. 2001, 51, 1043-1059. [CrossRef]

44. Vasudevan, M.; Kumar, G.S.; Nambi, I.M. Numerical study on kinetic/equilibrium behaviour of dissolution of toluene under variable subsurface conditions. Eur. J. Environ. Civ. Eng. 2014, 18, 1070-1093. [CrossRef]

45. Jean, J.S.; Tsai, C.L.; Ju, S.H.; Tsao, C.W.; Wang, S.M. Biodegradation and transport of benzene, toluene, and xylenes in a simulated aquifer: Comparison of modelled and experimental results. Hydrol. Processes 2002, 16, 3151-3168. [CrossRef]

46. Delle Site, A. Factors affecting sorption of organic compounds in natural sorbent/water systems and sorption coefficients for selected pollutants. A review. J. Phys. Chem. Ref. Data 2001, 30, 187-439. [CrossRef]

47. Ball, W.P.; Roberts, P.V. Long-term sorption of halogenated organic chemicals by aquifer material. 1. Equilibrium. Environ. Sci. Technol. 1991, 25, 1223-1237. [CrossRef]

48. Lagas, P. Sorption of chlorophenols in the soil. Chemosphere 1988, 17, 205-216. [CrossRef]

49. Mackay, D.M.; Freyberg, D.; Roberts, P.; Cherry, J. A natural gradient experiment on solute transport in a sand aquifer: 1. Approach and overview of plume movement. Water Resour. Res. 1986, 22, 2017-2029. [CrossRef] 